Research Article

\title{
Japanese encephalitis virus infection in an endemic area: hospital based study 1998 to 2000
}

\author{
Gunasekera H.A.K.M, ${ }^{1}$ Senanayake C.P,${ }^{2}$ Mendis L. ${ }^{3}$ Sunil Chandra N.P ${ }^{1}$ \\ Sri Lanka Journal of Infectious Diseases 2012 Vol.1(2);19-27 \\ DOI: http://dx.doi.org/10.4038/sljid.v2i1.3321 \\ Key words: Japanese encephalitis; AFRIMS; ELISA; Gampaha; Sri Lanka
}

\begin{abstract}
The Gampaha Deputy Provincial Director of Health Services (DPDHS) division reported a large number of Japanese encephalitis (JE) cases during 1996 to 1997. Notified cases included unconfirmed and confirmed cases. A study to determine the true disease burden was considered necessary. The proportion of undifferentiated fever cases due to Japanese encephalitis virus (JEV) varies in different populations and the Sri Lankan situation is not known. The objectives were to determine the proportion of undifferentiated fever cases and encephalitis cases due to $\mathrm{JEV}$ and the case fatality rate and frequency of neurological sequelae in JE in a tertiary care hospital in Gampaha. A cross-sectional descriptive study was carried out in the paediatric and medicine units of the North Colombo Teaching Hospital, Ragamafrom 1998 to 2000. Ninety three randomly selected patients with a diagnosis of undifferentiated fever from whom paired sera could be collected and 32 patients suspected of encephalitis which were not overtly due to mumps, measles or chicken-pox were included. The Armed Forces Research Institute in Medical Sciences Enzyme linked immunosorbent assay for anti-JEV immunoglobulin $\mathrm{M}$ and $\mathrm{G}$ was used to confirm JEV infection. One of $93(1.08 \%)$ undifferentiated fever cases was due to JEV infection. Eleven of 32 (34.38\%) encephalitis cases had JEV infection and $3(27.3 \%)$ had IgM antibodies to JEV in cerebrospinal fluid. Case fatality rate and sequelae at discharge were $11.1 \%$ each. JEV was an important cause of encephalitis in Gampaha during this period.
\end{abstract}

${ }^{1}$ Department of Microbiology, Faculty of Medicine, University of Kelaniya, Sri Lanka

${ }^{2}$ Department of Microbiology, Faculty of Medicine, Colombo, Sri Lanka

${ }^{3}$ Emeritus Professor of Microbiology, University of Colombo. President Sri Lanka Medical Council Chairperson, WHO-SEARO-ITAG

Address for correspondence: Dr. H.A.K.M. Gunasekera, Senior Lecturer, Dept. of Microbiology, Faculty of Medical Sciences, University of Sri Jayewardenepura, Sri Lanka. Email: kamani.lk@gmail.com Telephone No.94-011-2865834 Fax No.94-011-2801480 


\section{Introduction}

The Japanese encephalitis virus (JEV) was first isolated in Sri Lanka by Hermon and Anandarajah in 1968 from the serum of a child admitted to hospital in a comatose state. ${ }^{1}$ Serological surveys done in various parts of the island in 1976 and 1977 identified certain regions as endemic for JEV infections. The western coastal belt extending from Kalutara in the south up to Puttalam in the north and extending inland for about 10-15 miles to include Gampaha were found to be endemic for JEV. ${ }^{2}$

Based on data obtained from the Annual Health Bulletin, The Gampaha Deputy Provincial Director of Health Services (DPDHS) division was one of the divisions reporting a relatively large number of JEV cases during $1996^{3}-1997 .^{4}$ Except for a seroprevalence study in the Ragama area in $1988^{5}$, there are no recent published studies carried out in the Gampaha District for JEV infections.

The number of viral encephalitis cases notified to the Sri Lanka Epidemiology Unit include both laboratory confirmed and unconfirmed cases. Therefore, a study to determine the true disease burden of JEV infection based on laboratory confirmed results was considered necessary.

Most JEV infections do not result in overt illness. As reviewed by Vaughn and Hoke the ratio of apparent to inapparent infection may be different in different populations, andbetween 50 and 300 infections occur for each clinical case of encephalitis that is identified. ${ }^{6}$ Monath has estimated a more critical ratio of 200:1 to $300: 1 .^{7}$

JEV infections may present as an undifferentiated fever, aseptic meningitis or as encephalitis. ${ }^{8}$ Several studies done in Southeast Asian countries have shown that JEV contributes to a group of fevers known as undifferentiated fevers (viral fevers). Most studies in Sri Lanka have been on patients presenting with encephalitis. There is no documentation in peer reviewed journals of studies determining the proportion of JEV infections among patients with undifferentiated fevers in Sri Lanka. This study was designed to determine the morbidity caused by JEV in an endemic area, which would indicate the true disease burden.

\section{Material and Methods}

\section{Study population:}

Case definition for patients with nonbacterial undifferentiated fever: 1) History of fever or recordable temperature after admission of $>37.2^{\circ} \mathrm{C}\left(>99^{\circ} \mathrm{F}\right)$; 2) A peripheral white blood cell (WBC) count that did not show elevated total WBC with elevated neutrophil counts (to exclude possible bacterial infections); no definitive diagnosis at the time of discharge, therefore classed as "viral fever".

Case definition for patients with viral encephalitis: Patients with a history of fever or recordable temperature after admission of $>37.2^{\circ} \mathrm{C}\left(>99^{\circ} \mathrm{F}\right)$ together with altered sensorium were 
included in this study group. Encephalitis cases overtly associated with mumps, measles or chicken-pox were excluded.

Two hundred and seven patients admitted to the paediatric and adult medicine professorial units of the North Colombo Teaching Hospital, Ragama were recruited from March 1998 to July 1999. The first three patients that fit the definition for undifferentiated fever and who consented to participate in the study were selected from each ward on the same day every week during the study period. Patients were followed up until discharge and if the diagnosis changed at the time of discharge, those patients were excluded from the study. Paired sera were available from only 93 patients and therefore laboratory tests were performed on only these patients.

Thirty two consecutive cases of clinically suspected viral encephalitis, admitted to the paediatric and adult medicine professorial units of the North Colombo Teaching Hospital, Ragama, between March 1998 and July 2000 were studied.

\section{Specimen collection}

Paired sera were collected from each patient. The first specimen was collected soon after admission and the second specimen ten days later. Encephalitis patients who were transferred from base hospitals had the first sample collected soon after transfer to this hospital. Informed written consent was obtained from all individuals included in the study or from their guardian when they were not competent to give consent. Cerebrospinal fluid (CSF) specimens were collected whenever possible from patients diagnosed as viral encephalitis. Serum and CSF were stored at $-20^{\circ} \mathrm{C}$ until tested for JEV antibodies.

\section{Laboratory methods}

The U.S. Armed Forces Research Institute of Medical Sciences (AFRIMS, Bangkok, Thailand) reference enzyme immunoassay (EIA) for dengue and JEV was used for diagnosing JEV infection. The EIA was performed in January 2004, as described previously. ${ }^{9,10}$ All samples were tested in parallel for antibodies against dengue and JEV. A few modifications done subsequently by the AFRIMS laboratory were followed, as given below. The dilution of the goat anti-human $\operatorname{IgM}$ and $\operatorname{IgG}$ antibodies used for sensitizing the microtiter plates was changed to $1: 1400$ in $6 \mathrm{mM}$ carbonate-bicarbonate buffer. Dengue and JEV antigens were diluted in phosphate buffered saline plus $13.5 \%$ (previously 20\%) acetone extracted normal human serum and were incubated for two hours at room temperature, not overnight. The conjugate was prepared in $13.5 \%$ acetone extracted normal human serum containing $0.5 \%$ bovine serum albumin. Interpretation of results and classification of dengue infection status was as described previously.,

\section{Statistically analysis}

SPSS Version 10.0 for Windows was used for analysis of data. 


\section{Results}

One of $93(1.08 \%)$ undifferentiated fever cases was due to JEV infection as diagnosed by the EIA. This patient was a 15 year old male who had not been vaccinated against JEV. The duration of hospitalization for this patient was two days.

Of the 32 patients diagnosed as viral encephalitis, $9(28.1 \%)$ were from the paediatric and 23 (71.9\%) from the adult medicine wards. Nineteen (59.4\%) were males. Age ranged from two years and 11 months to 71 years (Mean 25.88 years, $\mathrm{SD}=18.69$; Median 18.50 years). Twenty eight $(78.1 \%)$ patients were sinhalese, with $3(9.4 \%)$ tamils and 1 (3.1\%) muslim patient. Information was not available in $3(9.4 \%)$.

Six $(18.5 \%)$ of the viral encephalitis patients were not residents of the Gampaha District. Except for five $(15.6 \%)$ who had been in the district for only a few months, the others had been resident in the district for more than one year. Information regarding place of residence was not available from six $(18.5 \%)$ patients.

Eleven out of $32(34.38 \%)$ patients with viral encephalitis had evidence of JEV infection. Three $(27.3 \%)$ of these eleven patients had anti-JE IgM >40 EIA units in the CSF, and therefore were confirmed as Japanese encephalitis. The other eight $(72.7 \%)$ patients were diagnosed as recent JEV infection as CSF samples were not available for testing.

In 10 of $32(31.3 \%)$ viral encephalitis patients only an acute serum was available, collected 6 days or later from the onset of illness (range 6-30 days). Information on date of onset of illness was not available from two patients, therefore the duration of illness before collection of the first serum specimen is not known. Seven of the ten who had only acute serum were negative for JEV infection. Duration of illness before collection of first serum specimen ranged from 6-19 days in these seven patients negative for JEV infection.

Three of $16(18.8 \%)$ viral encephalitis patients under 18 years and eight of $16(50.0 \%)$ patients in the $\geq 18$ year age group were diagnosed as due to JEV infection. There was a marginally significant difference between these proportions indicating that a significantly higher proportion of adult encephalitis cases were due to JEV ( $\mathrm{z}$ score $=1.97 ; \mathrm{p}<0.049$ ). The age of JE patients ranged from 12 to 71 years.

The male to female ratio was 1.2:1.0 among JE cases. Among viral encephalitis patients, 6 of 19 (31.6\%) males and 5 of $13(38.5 \%)$ females had encephalitis due to JEV infection. There was no significant difference in the proportion of JEV infection in males as compared to females $(\mathrm{p}>0.05)$.

Three JE patients were not residents of the Gampaha District. The duration of hospital stay for the JE cases ranged from 3-38 days (mean 12.1 days, $\mathrm{SD}=9.87$; median 11.0 days). One patient died in hospital and two patients were transferred to local hospitals and therefore were lost to follow up. 
The level of consciousness ranged from a Glasgow Coma Scale (GCS) score of 7 to 15 at the time of admission. During hospitalization only four patients showed deteriorating levels of consciousness from the levels recorded at admission. The lowest GCS score recorded during hospitalization in these patients ranged from 5 to 14 (one patient was lost for follow up when transferred).

Abnormal neurological findings included neck stiffness in 9/10 patients $(90.0 \%)$, brisk deep tendon reflexes in $5 / 10$ patients $(50.0 \%$ ), increased muscle tone in $3 / 10$ patients $(30.0 \%)$, involuntary movements in $2 / 10$ patients $(20.0 \%)$, hemiparesis in $1 / 10$ patients $(10.0 \%)$; slurred speech and recent memory loss in $1 / 10$ patients $(10.0 \%)$. Three $(30.0 \%)$ patients developed convulsions. On examination of the optic fundus, blurred disc margins and congestion were observed in $5 / 10$ patients $(50.0 \%)$.

Except for one patient who was too restless to have an electroencephalogram (EEG) done, all the others had slow wave activity in the EEG.

Outcome of illness was known only in 9/11 JE cases. One patient died, giving a case fatality rate of $11.1 \%$ for JE cases. 8 patients did not have any residual neurological abnormality at the time of discharge, but 1 patient $(11.1 \%)$ had recent memory loss.

Vaccination status was known in 10/11 patients diagnosed as having Japanese encephalitisand none had been vaccinated against JEV. None of the patients infected with JEV worked in paddy fields, or had occupations which required close contact with animals.

\section{Discussion}

The available information on the proportion of JEV infections among undifferentiated fever cases varies greatly in different populations. In the present study $1.08 \%$ (1/93) of undifferentiated cases was due to JEV. In a study in Thailand, 14\% (22/156) of adult patients presenting with acute undifferentiated fever were due to JEV. ${ }^{11}$ In a study carried out in Penang, Malaysia, among paediatric patients with non-specific febrile illness, $0.4 \%$ (2/482) were due to JEV infection during 1990 to $1992 .{ }^{12}$ In another study conducted in 1967 in South Vietnam among American servicemen presenting with acute pyrexia of unknown origin, 6.8\% (54/793) of cases were attributed to JEV. ${ }^{13}$

One of the reasons for the low number of JEV infections among undifferentiated fever cases in the present study may be due to the fact that $30.1 \%$ of patients in the undifferentiated fever group were children who had been immunized against JEV. Almost all of the adult patients in this group had been resident in the Gampaha District for more than one year and had probably been previously exposed to the JEV and were therefore protected from disease. In previous studies, nearly all Thai adults in Chiangmai, Thailand, were shown to be infected by the age of 30 years and it has been suggested that previous infection with JEV protects against disease to a greater extent than it protects against re-infection. ${ }^{14}$ 
Cases of undifferentiated fever negative for JEV infection may have been due to infections such as influenza, infectious mononucleosis, chikungunya, leptospirosis, typhoid, or rickettsial diseases.

Eleven of 32 (34.38\%) patients with viral encephalitis in the present study had evidence of JEV infection. Three of the 11 patients could be confirmed as JE as CSF samples from these patients were positive for JE-IgM antibodies by the EIA. In the remaining eight patients only serum samples were tested but half of these cases had paired serum samples which demonstrated increasing levels of JE-IgM antibodies, and therefore could be considered as confirmation of a current infection.

Out of seven viral encephalitis patients with only an acute serum available and who were found negative for JEV infection, the duration of illness before collection of the acute sample was not known in two patients and therefore JEV infection in these two patients cannot be excluded. Of the remaining five patients, four patients had acute serum samples collected more than seven days from the onset of illness, while in one patient it had been collected on the sixth day of illness. JEV specific IgM can be detected in CSF, serum or both in all patients with JE by the seventh day after onset. ${ }^{8,15,16}$ Therefore, the causative agent of encephalitis is unlikely to be JEV in the four patients who had acute serum collected later than seven days but it cannot be safely excluded in the patient with an acute serum collected on the sixth day of illness.

JEV is an important cause of viral encephalitis in endemic areas of Sri Lanka as seen from the present study where more than one third of patients with viral encephalitis had evidence of JEV infection. A limited serological study done on specimens received from encephalitis patients during 1972-1981 at the Medical Research Institute of Colombo has shown that JEV accounted for $43.3 \%$ of cases and was the leading cause of encephalitis in Sri Lanka. ${ }^{17}$ During the 1985 outbreak in the Anuradhapura District 36.8\% (120/326) clinically suspected cases were confirmed as due to $\mathrm{JEV}^{18}$ and in the 1987 outbreak 48.5\% (361/744) were found to be due to JEV. ${ }^{19}$ Similar high percentages of JE cases among viral encephalitis patients have been recorded in Southeast Asian countries in the past. ${ }^{20-23}$

The viral encephalitis cases that were negative for JEV infection in the present study may have been due to other common aetiological agents such as mumps, measles, enteroviruses such as coxsackie and echo, herpes simplex, and adenoviruses. Bacterial and tuberculous meningitis also fall into the differential diagnoses when biochemical findings and the cellular changes in the CSF are not conclusive. Cerebral malaria and Reye's syndrome also present with a similar clinical picture.

The number of JE patients identified in the present study is inadequate to arrive at a definite conclusion as to the age distribution pattern of JE cases in this study. It appears that there was a marginally significant difference in the proportion of JE patients in the more than 18 year age group as opposed to patients under 18 years but a larger number of patients would be required to establish this fact. Since JE immunization has been initiated in the Gampaha District since 1996 it might be expected that the number of JE cases in children would reduce and the age 
distribution of JE cases would shift to an older age group as has been seen in other countries where JE has been brought under control through immunization. ${ }^{23,24}$

The male to female ratio of JE cases in the present study was 1.2:1.0. In the outbreak investigation of Anuradhapura in 1985 the incidence in males was found to be 1.5 times higher than in females. ${ }^{25}$ A male preponderance has been seen among JE cases in other countries too. $^{21,22,26,27}$

For the confirmed JE cases with known outcome, the case fatality rate and the percentage with residual neurological abnormalities at discharge was $11.1 \%$ each. Since these patients were not followed up after discharge it is not possible to comment if these sequelae persisted or if late sequelae such as fits occurred. The JE patient who died developed apnoeic attacks but was not intubated and had to be managed in the ward due to non-availability of beds in the intensive care unit. His GCS score at admission was 14 and there was no rapid progression to coma. Low levels of consciousness at admission and rapid progression to coma have previously been identified as risk factors for a fatal outcome. ${ }^{28}$

The case fatality rate in this study is lower than reported in the past. From 1971 to 1980 , an average of 1030 encephalitis patients was admitted to hospitals and $43 \%$ of these were diagnosed as JEV infections. The case fatality rate averaged $38 \%(25-45 \%)$ during this period. ${ }^{2}$ The case fatality rate during the 1985 outbreak in Anuradhapura was $19.9 \%{ }^{18}$ High case fatality rates for JE have been reported from other countries which range from $10-50 \% .^{22,26,27,28}$

In conclusion JEV infection was a major cause of encephalitis in patients residing in the Gampaha district and the need for the current immunization programme in this area is clearly justified.

\section{References}

1. Hermon YE, Anandarajah M. Isolation of Japanese Encephalitis virus from the serum of a child in Ceylon. Ceylon Med J 1974; 19(2):93-9. No doi.

2. Vitarana T. Japanese encephalitis: A problem in Sri Lanka. Bulletin of Medical Research Institute of Sri Lanka 1986; 2:55-60. No doi.

3. Epidemiology Unit, Ministry of Health, Sri Lanka. Annual Health Bulletin 1996:103. No doi.

4. Epidemiology Unit, Ministry of Health, Sri Lanka Annual Health Bulletin 1997:105. No doi.

5. Peiris JSM, Amerasinghe FP, Arunagiri CK, Perera LP, Karunaratne SHPP, Ratnayake CB, Kulatilaka TA et al. Japanese encephalitis in Sri Lanka: comparison of vector and virus ecology in different agro-climatic areas. Trans R Soc Trop Med Hyg 1993; 87(5):541-8.

6. Vaughn DW, Hoke CH Jr. The epidemiology of Japanese encephalitis: prospects for prevention. Epidemiol Rev 1992; 14:197-221. No doi

7. Monath TP, Heinz FX. Flaviviruses. In: Fields BN, Knipe DM, Howley PM, et al., eds. Fields Virology, 3rd ed. Philadelphia: Lippincott-Raven Publishers, 1996:961-1022. No doi

8. Petersen LR, Gubler DJ. Flaviviruses. In: Warrell DA, Cox TM, Firth JD, Benz EJ Jr, eds. Oxford Textbook of Medicine. 4th ed. Volume 1. New York: Oxford University Press Inc., 2003:382-389. No doi 
9. Innis BL, Nisalak A, Nimmannitya S, Kusalerdchariya V, Chongswasdi S, Suntayakorn P et al. An Enzyme-linked immunosorbent assay to characterize dengue infections where dengue and Japanese encephalitis co-circulate. Am J Trop Med Hyg 1989; 40(4):418-27. No doi

10. Vaughn DW, Nisalak A, Solomon T, Kalayanarooj S, Nguyen MD, Kneen R et al. Rapid serologic diagnosis of dengue virus infection using a commercial capture EIA that distinguishes primary and secondary infections. Am J Trop Med Hyg 1999; 60(4):693-8. No doi

11. Watt G, Jongsakul K. Acute undifferentiated fever caused by infection with Japanese encephalitis virus. Am J Trop Med Hyg 2003; 68(6):704-6. Available from: http://www.ajtmh.org/content/68/6/704.full.pdf+html (accessed 16 ${ }^{\text {th }}$ Aug 2011). No doi

12. Cardosa MJ, Hooi TP, Kaur P. Japanese encephalitis virus is an important cause of encephalitis among children in Penang. Southeast Asian J Trop Med Public Health 1995; 26(2):272-5. No doi

13. Berman SJ, Irving GS, Kundin WD, Gunning JJ, Watten RH. Epidemiology of the acute fevers of unknown origin in South Vietnam: effect of laboratory support upon clinical diagnosis. Am J Trop Med Hyg 1973; 22(6):796-801. No doi

14. Grossman RA, Edelman R, Willhight M, Pantuwatana S, Udomsakdi S. Study of Japanese encephalitis virus in Chiangmai Valley, Thailand; III. Human seroepidemiology and inapparent infections. Am J Epidemiol 1973; 98(2):133-49. No doi

15. Burke DS, Nisalak A, Ussery MA, Laorakpongse T, Chantavibul S. Kinetics of IgM and IgG responses to Japanese encephalitis virus in human serum and cerebrospinal fluid. J Infect Dis 1985; 151(6):1093-9. No doi

16. Han XY, Ren QW, Xu ZY, Tsai TF. Serum and cerebrospinal fluid immunoglobulins M, A, and $\mathrm{G}$ in Japanese encephalitis. J ClinMicrobiol 1988; 26(5):976-8.Available from:http://www.ncbi.nlm.nih.gov/pmc/articles/PMC266499/pdf/jcm00077-0208.pdf (accessed 16 ${ }^{\text {th }}$ Aug 2011) No doi.

17. Vitarana T. Viral diseases in Sri Lanka - A national overview. In: Mackenzie JS, ed. Viral diseases in Southeast Asia and the Western Pacific. London: Academic Press, 1982:198-204. No doi.

18. Abeysinghe MRN. Some epidemiological aspects of the outbreak of Japanese encephalitis in Anuradhapura District, Sri Lanka, 1985-86. Dissertation submitted to the Post Graduate Institute of Medicine of the University of Colombo for a Master of Science, 1987; 1-2 pp. No doi.

19. Peiris JSM, Amerasinghe FP, Amerasinghe PH, Ratnayake CB, Karunaratne SHPP, Tsai TF. Japanese encephalitis in Sri Lanka - the study of an epidemic; vector incrimination, porcine infection and human disease. Tran $R$ Soc Trop Med Hyg 1992; 86(3):307-13. doi:10.1016/0035-9203(92)90325-7

20. Nathin MA, Harun SR, Sumarmo. Dengue haemorrhagic fever and Japanese B encephalitis in Indonesia. Southeast Asian J Trop Med PublicHealth 1988; 19(3):475-81. No doi.

21. Sinniah M. A review of Japanese-B virus encephalitis in Malaysia. Southeast Asian J Trop Med PublicHealth 1989; 20(4):581-85. No doi.

22. Chunsuttiwat S. Japanese encephalitis in Thailand. Southeast Asian J Trop Med Public Health 1989; 20(4):593-8. No doi. 
23. Mukherjee KK, Chakravarti SK, Mukherjee MK, Dee PN, Chatterjee S, Chatterjee P, et al. Recurrent outbreaks of Japanese encephalitis in Nagaland (1985-1989) - A seroepidemiological study. J Comm Dis 1991; 23(1):11-7. No doi.

24. Tsai TF. New initiatives for the control of Japanese encephalitis by vaccination: Minutes of a WHO/CVI meeting, Bangkok, Thailand, 13-15 October 1998. Vaccine 2000; 18(Suppl 2):125. doi:10.1016/S0264-410X(00)00037-2

25. Wu YC, Huang YS, Chien LJ, Lin TL, Yueh YY, Tseng WL, et al. The epidemiology of Japanese encephalitis in Taiwan during 1966-1997. Am J Trop Med Hyg 1999; 61(1):78-84. Available from: http://www.aitmh.org/content/61/1/78.long (accessed $16^{\text {th }}$ Aug 2011). No doi.

26. Umenai T, Krzysko R, Bektimirov A, Assaad FA. Japanese encephalitis: current worldwide status. Bull World Health Organ 1985; 63(4):625-31. Available from: http://www.ncbi.nlm.nih.gov/pmc/articles/PMC2536386/pdf/bullwho00087-0002.pdf (accessed $16^{\text {th }}$ Aug 2011) No doi.

27. Chaudhuri N, Shaw BP, Mondal KC, Maity CR. Epidemiology of Japanese encephalitis. Indian Paediatr 1992; 29:861-65.No doi.

28. Burke DS, Lorsomrudee W, Leake CJ, et al. Fatal outcome in Japanese encephalitis. Am J Trop Med Hyg 1985; 34(6):1203-10. No doi. 